\title{
FREE VOLUME IN PLASTIFIED POLY(VINYL CHLORATE)
}

\author{
J. BOREK \\ Institute of Chemistry, Silesian University, Szkolna 9, 40-006 Katowice, Poland \\ AND W. OSOBA \\ Institute of Physics, Silesian University, Uniwersytecka 4, 40-007 Katowice, Poland
}

\begin{abstract}
Positron lifetimes measurements in pure poly(vinyl chlorate) (PVC) and in plastified PVC were performed. Three different plasticizers were used: dibutyl phtalate, dioctyl phtalate and tricresyl phosphate. The measured samples were prepared of PVC with two different plasticizers concentration ( $20 \%$ and $30 \%$ of the plasticizers in the poly(vinyl chlorate)). All the measurements were performed in air at room temperature. A conventional fast-slow coincidence lifetime spectrometer was used for the measurements. Free volume radii were calculated from the lifetime data.
\end{abstract}

PACS numbers: $71.60 .+\mathrm{z}, 78.70 . \mathrm{Bj}$

\section{Introduction}

Polymers have been investigated intensively for years. Among numerous techniques which are used for this purpose, positron annihilation spectroscopy plays a very important role [1-4]. This technique is widely used for investigation different aspects of polymer properties and positron behaviour in polymers. When a positron, emitted from a radioactive source, enters into condensed matter, it quickly loses its kinetic energy and reaches thermal energies. The thermalised positron can annihilate as a free particle or may form a bound system - positronium (Ps). It seems that the positron may form the Ps atom in amorphous region of polymer substance where electron density is low. In these regions free volumes exist where orthopositronium (o-Ps) may live for several ns. Many external factors perturb or influence positron lifetimes in polymer matter. The temperature dependence of the positron lifetimes in polymers is presented in Refs. [5-8]. The positron annihilation dependence on pressure is discussed, for instance, in Refs. $[9,10]$. The influence of magnetic fields on positron annihilation in polymers is discussed in Refs. [11, 12]. The different degree of crystallinity of polymers also affects the positron lifetimes [13]. The influence of plasticizers on positron annihilation in polymers is presented in Ref. [14]. In this paper we present some preliminary results of positron lifetime measurements in poly(vinyl chlorate) with two different $(20 \%$ and $30 \%)$ concentration of three plasticizers. Dibutyl phtalate, dioctyl phtalate and tricresyl phosphate have been chosen as the plasticizers. 


\section{Experimental}

All the measurements were performed in air at room temperature. A conventional slow-fast coincidence spectrometer with plastic crystals was used. The time resolution of the spectrometer, approximated by one Gaussian curve, was determined by analysing the positron lifetimes in kapton foils with the aid of the computer package programs PATFIT-88 [15]. The resolution, defined in this manner, equalled about $320 \mathrm{ps}$.

Several droplets of a carrier free solution of ${ }^{22} \mathrm{NaCl}$ were deposited and then evaporated on a piece of kapton foil $\left(1.1 \mathrm{mg} / \mathrm{cm}^{2}\right)$. Another piece of the foil has been sealed over the first one to form a positron source with activity about $0.3 \mathrm{MBq}$. During all the measurements the source was sandwiched between two identical samples of investigated polymer. Positron lifetime spectra were accumulated to approximately $3 \times 10^{6}$ counts. The measurements were repeated twice for some samples. A source correction was not not taken into account during numerical valuations. follows:

Chemical formulae of the investigated polymer and the plasticizers are as

1. poly(vinyl chlorate)<smiles>[3H]C([18F])C([3H])Cl</smiles>

2. dibutyl phtalate<smiles>CCCCOC(=O)OCCCC</smiles>

3. dioctyl phtalate<smiles>CCCCCCCCCCCCC(=O)OCC</smiles>

4. tricrcsyl phosphate<smiles>CCOP(=O)(O[Pb])O[Pb]C</smiles>

All the plasticizers are esters and are known as the first range plasticizers. Dibutyl phtalate and dioctyl phtalate are organic esters with different length of carbon chains. All the measured samples were made of paste-making PVC produced by 
Zakłady Chemiczne Oświęcim (Poland) as a commercial product E-68. Its average molecular weight equals 85000 . The polymer powder was mixed with different $(20 \%$ and $30 \%$ by weight) amounts of plasticizer. The mixture was carefully homogenized and then was heated up till $408 \mathrm{~K}$. The warm mixture was pressed (10 MPa) to form the disc-shaped samples about $3 \mathrm{~mm}$ thick and $9 \mathrm{~mm}$ in diameter. X-ray diffraction studies were performed to estimate the degree of crystallinity of the samples. They proved that all the samples were amorphous as X-ray diffraction pattcrns were very broad and indefinite.

\section{Results}

The typical positron lifetime spectrum for one of the samples is shown in Fig. 1. The spectra were analysed using the package programs PATFIT-88. These programs fitted three or four components to the measured spectra with the shortest lived component fixed at $125 \mathrm{ps}$. For the four-component analysis turned out to be ambiguous, only the three-component analysis results are presented in this paper.

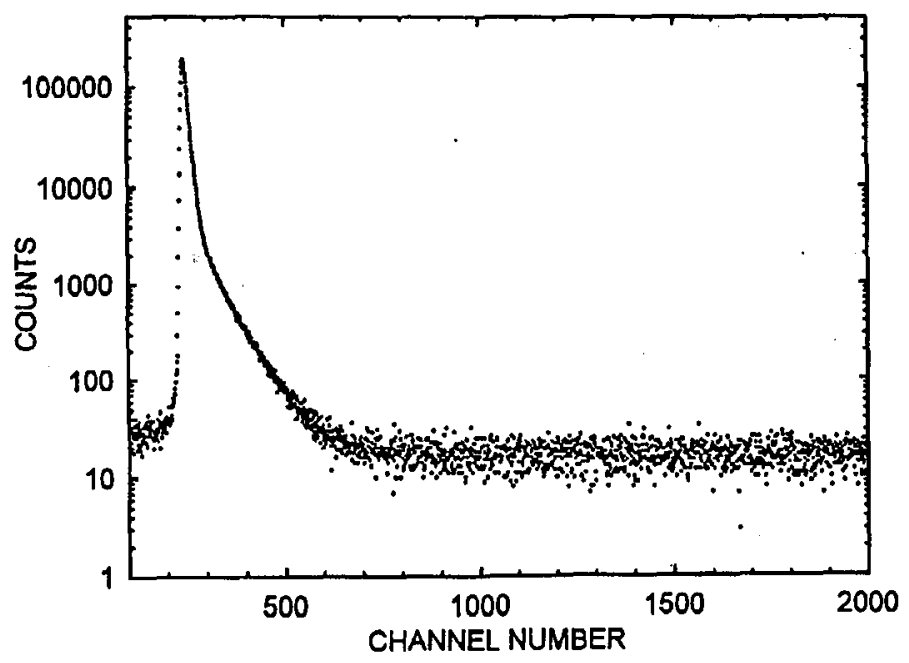

Fig. 1. The positron lifetime spectrum for poly (vinyl chlorate) with $30 \%$ of the dibutyl phtalate admixture.

The shortest lived component (in these cases fixed at $\tau_{1}=125 \mathrm{ps}$ ) is attributed to $p$-Ps annihilation [16-18]. The intermediate component, $\tau_{2}$, describes the annihilation of the free positrons and finally the longest lived component, $\tau_{3}$, is attributed to the pick-off annihilation of o-Ps. According to a model proposed by Tao [19] and Eldrup with co-workers [20] the longest lived component of the positron lifetime spectrum may be correlated with the radius of a free volume cavity in the polymer matter. They derived an equation

$$
\tau_{3}=0.5\{1-R /(R+0.1656)+1 / 2 \pi \sin [2 \pi R /(R+0.1656)]\}^{-1},
$$

where $\tau_{3}$ is the $o$-Ps lifetime expressed in nanoseconds, $R$ is the radius of the 
TABLE

Intensities, lifetimes and $R$ values obtained for samples made of PVC and PVC with different plasticizers.

\begin{tabular}{c|c|c|c|c|c|c}
\hline \hline Sample & $I_{2}[\%]$ & $I_{3}[\%]$ & $\tau_{2}[\mathrm{ps}]$ & $\tau_{3}[\mathrm{ps}]$ & Variance & $R[\mathrm{~nm}]$ \\
\hline PVC (pure) & 91.80 & 5.39 & 387.2 & 1730.3 & 2.74 & 0.259 \\
& \pm 0.19 & \pm 0.07 & \pm 0.3 & \pm 12.0 & & \pm 0.001 \\
\hline PVC+20\% & 87.90 & 7.81 & 380.3 & 2004.9 & 1.27 & 0.285 \\
dibutyl phtalate & \pm 0.32 & \pm 0.07 & \pm 1.0 & \pm 12.1 & & \pm 0.001 \\
\hline PVC+30\% & 86.91 & 9.47 & 363.4 & 2177.9 & 1.50 & 0.301 \\
dibutyl phtalate & \pm 0.19 & \pm 0.37 & \pm 0.5 & \pm 6.2 & & \pm 0.001 \\
\hline PVC+20\% & 88.94 & 7.41 & 362.5 & 1979.6 & 1.25 & 0.283 \\
dioctyl phtalate & \pm 0.23 & \pm 0.04 & \pm 0.7 & \pm 8.2 & & \pm 0.001 \\
\hline PVC+30\% & 87.22 & 8.74 & 377.2 & 2264.5 & 1.25 & 0.308 \\
dioctyl phtalate & \pm 0.24 & \pm 0.04 & \pm 0.8 & \pm 8.5 & & \pm 0.001 \\
\hline PVC+20\% & 85.91 & 8.04 & 364.2 & 1774.0 & 1.29 & 0.263 \\
tricresyl phosph. & \pm 0.27 & \pm 0.06 & \pm 0.9 & \pm 8.6 & & \pm 0.001 \\
\hline PVC+30\% & 89.72 & 9.84 & 362.7 & 1980.5 & 1.17 & 0.283 \\
tricresyl phosph. & \pm 0.44 & \pm 0.07 & \pm 1.1 & \pm 9.5 & & \pm 0.001
\end{tabular}

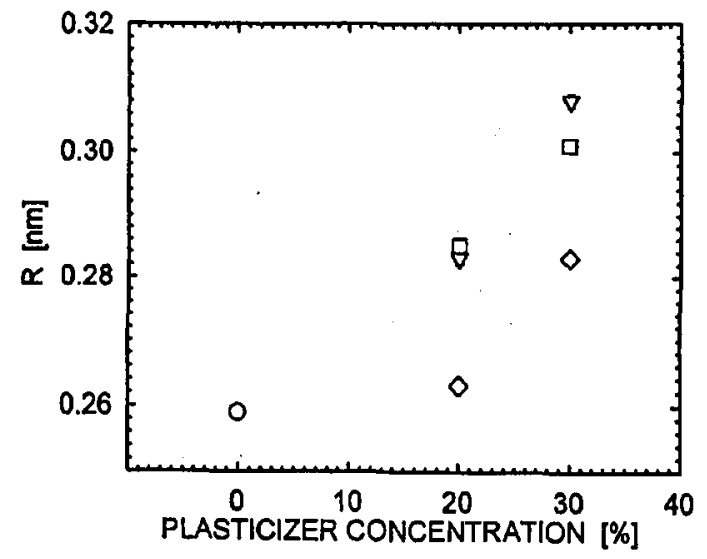

Fig. 2. The radii of the spherical wells versus the plasticizers concentration. A circle: PVC (pure); squares: PVC + dibutyl phtalate; triangles: PVC + dioctyl phtalate; diamonds: PVC + tricresyl phosphate. Errors are smaller than the diameter of the dots.

spherical well expressed in $\mathrm{nm}$ and $0.1656 \mathrm{~nm}$ is an empirical constant. The results i.e. lifetimes $\tau_{i}$, intensities $I_{i}$ and the $R$ values calculated according to Eq. (1) are listed in Table. In the cases when the measurements were repeated for the sample, weighted means of the results are listed.

In Fig. 2 the radii of the spherical wells are shown versus the concentration 
of the plasticizers. It is clear that the radii of the spherical wells increase as the concentration of the plasticizer increases. The biggest changes of the radii, as compared with the radii in pure poly(vinyl chlorate), are observed for the PVC+dioctyl phtalate. The less pronounced dependence of the radii on the concentration of the plasticizer is observed for the PVC + tricresyl phosphate. The comparison of these radii for the dibutyl phtalate and dioctyl phtalate admixtures seems to point at the simple relation between the length of the carbon chain and the values of the radii: the longer the carbon chain is the bigger the radius is. The measurements for the next concentration of the plasticizers are in progress.

\section{Acknowledgment}

The autors are deeply indebted to Dr. A. Ratuszna and her group (Solid State Physics Department, Silesian University) for their X-ray diffraction measurements of the samples.

\section{References}

[1] J.R. Stevens, Meth. Exp. Phys. A 16, 371 (1980).

[2] Y.C. Jean, D.M. Schrader, in: Positron and Positronium Chemistry, Eds. D.M. Schrader, Y.C. Jean, Elsevier, Amsterdam 1988, p. 91.

[3] H.J. Ache, in Ref. [2], p. 318.

[4] Y.C. Jean, Microchem. J. 42, 72 (1990).

[5] Q. Deng, F. Zandiehnadem, Y.C. Jean, Macromolecules 25, 1090 (1992).

[6] J. Kristiak, J. Bartos, K. Kristiakova, O. Sausa, P. Bandzuch, Phys. Rev. B 49, 6601 (1994).

[7] S.Y. Wang, Y.M. Shentu, H.D. Wang, T.B. Chang, Mater. Sci. Forum 105-110, 1787 (1992).

[8] S.Y. Wang, Y.M. Shentu, H.D. Wang, T.B. Chang, Mater. Sci. Forum 105-110, 1791 (1992).

[9] Y.Y. Wang, H. Nakanishi, Y.C. Jean, T.C. Sandreczki, J. Polym. Sci. B Polym. Phys. 28, 1431 (1990).

[10] Q. Deng, C.S. Sundar, Y.C. Jean, J. Phys. Chem. 96, 492 (1992).

[11] G. Consolati, F. Quasso, J. Phys. C 21, 4143 (1988).

[12] G. Consolati, F. Quasso, Acta Phys. Pol. A 83, 273 (1993).

[13] H. Nakanishi, Y.C. Jean, E.G. Smith, T.C. Sandreczki, J. Polym. Sci. B Polym. Phys. 27, 1419 (1989).

[14] T. Okada, S. Nishijima, Y. Honda, Y. Kobayashi, J. Phys. IV (France) 3, 291 (1993).

[15] P. Kirkegaard, N.J. Pedersen, M. Eldrup, Tech. Rep. Ris $\varnothing-M-2740$, Ris $\varnothing$ National Lab., Roskilde (Denmark) 1989.

[16] W. Brandt, Appl. Phys. 5, 1 (1974).

[17] W. Brandt, J. Wilkenfeld, Phys. Rev. B 12, 2759 (1975).

[18] P. Kindl, R. Reiter, Phys. Status Solidi A 104, 707 (1987).

[19] S.J. Tao, J. Chem. Phys. 56, 5499 (1972).

[20] M. Eldrup, D. Lightbody, J.N. Sherwood, Chem. Phys. 63, 51 (1981). 